\title{
A Macrocyclic Nickel(II) Complex Salt Containing Six-Coordinate Nickel(II) Ions in a Different Coordination Environment
}

\author{
Jin Suk Kwag, Hanyoung Park, Alan J. Lough, ${ }^{\dagger}$ and Ju Chang Kim* \\ Department of Chemistry, Pukyong National University, Busan 608-737, Korea.*E-mail: kimjc@pknu.ac.kr \\ ${ }^{\dagger}$ Department of Chemistry, University of Toronto, Toronto, ONT, Canada M5S $3 H 6$ \\ Received September 18, 2009, Accepted November 8, 2009
}

Key Words: Nickel(II) complex, Crystal structure, Macrocycle, Polycarboxylic acid

In aqueous solutions nickel(II) complexes of tetraazamacrocycles have been understood to exist in equilibrium as a mixture of orange square-planar and blue trans-diaqua octahedral species according to the following equation. ${ }^{1-5}$

$$
\begin{aligned}
& {[\mathrm{Ni}(\text { macrocycle })]^{2+}+} 2 \mathrm{H}_{2} \mathrm{O} \rightleftharpoons \\
& \text { trans }-\left[\mathrm{Ni}\left(\mathrm{OH}_{2}\right)_{2}(\text { macrocycle })\right]^{2+}
\end{aligned}
$$

The evidence for the equilibrium is the observation of lower molar extinction coefficients for the square-planar nickel(II) complexes in coordinating solvents than those in noncoordinating solvents. ${ }^{1,6}$ Although the equilibrium is susceptible to temperature, addition of salts, ionic strength, etc., it is difficult to shift the above equilibrium completely to the octahedral side. $^{1,2,7}$ Therefore, the isolated macrocyclic nickel(II) complexes are usually square-planar, and this is especially true when the perchlorate or hexafluorophosphate salts are added to the aqueous solutions of macrocyclic nickel(II) complexes in equilibrium. Later, the successful isolation of a trans-diaqua octahedral nickel(II) cyclam (cyclam $=1,4,8,11$-tetraazacyclotetradecane) has been appeared with its solid state X-ray structure as well as single crystal visible spectrum by Mochizuki and Kondo. ${ }^{4}$ Similarly, the equilibrium between a square-planar nickel(II) complex and a trans-diacetonitrile octahedral nickel (II) complex has been reported by spectrophotometric titration of the macrocyclic nickel(II) complex with acetonitrile in nitromethane solutions. ${ }^{8}$ Then, the diacetonitrile coordinated octahedral nickel(II) complex trans- $\left[\mathrm{Ni}\left(\mathrm{CH}_{3} \mathrm{CN}\right)_{2}(\mathbf{L 1})\right]\left(\mathrm{PF}_{6}\right)_{2}(\mathbf{L 1}=$ 3,14-dimethyl-2,6,13,17-tetraazatricyclo $\left[14,4,0^{1.18}, 0^{7.12}\right]$ docosane) has been isolated and structurally characterized. ${ }^{5}$ None the less, the examples of isolated and structurally characterized diaqua or diacetonitrile coordinated octahedral nickel(II) teraazamacrocyclic complexes are extremely rare.

In this report we describe the synthesis and structure of a new macrocyclic nickel(II) complex $\left[\mathrm{Ni}(\mathbf{L 1})\left(\mathrm{H}_{2} \mathrm{O}\right)_{2}\right][\mathrm{Ni}(\mathbf{L 1})$ bis $\left(\mathrm{H}_{2}\right.$ thftc)] $4 \mathrm{H}_{2} \mathrm{O}(\mathbf{1})$ (thftc $=$ tetrahydrofuran-2r,3t,4t,5c-tetracarboxylate) in which each nickel(II) ion is under an octahedral coordination environment. Thus, the coordination environment of nickel(II) ion in the $\left[\mathrm{Ni}(\mathbf{L 1})\left(\mathrm{H}_{2} \mathrm{O}\right)_{2}\right]^{2+}$ dication is composed of a tetraazamacrocycle $\mathbf{L} \mathbf{1}$ and axially coordinated aqua ligands, and the nickel(II) ion in the dianion $\left[\mathrm{Ni}(\mathbf{L 1}) \text { bis }\left(\mathrm{H}_{2} \mathrm{thftc}\right)\right]^{2-}$ is coordinated by the macrocycle $\mathbf{L} \mathbf{1}$ and two monodentate $\mathrm{H}_{2}$ thftc ligands axially. The macrocyclic nickel(II) dication is connected to the macrocyclic nickel(II) dianion by the mediation of lattice water molecules through hydrogen bonds.

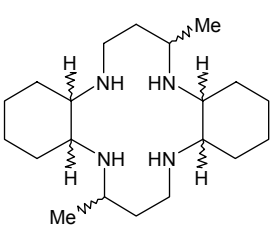

$\mathbf{L}$

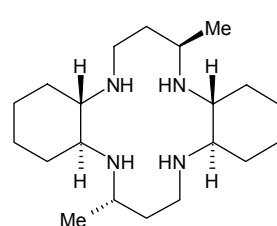

L1<smiles>O=C(O)C1OC(C(=O)O)C(C(=O)O)C1C(=O)O</smiles>

$\mathrm{H}_{4}$ thftc
Experimental Section

Materials, Methods and Apparatus. All chemicals used in the synthesis were of reagent grade and used without further purification. Distilled water was used for all procedures. Infrared spectra of solid samples were recorded on a Perkin-Elmer Paragon 1000 FT-IR spectrophotometer between $4000 \mathrm{~cm}^{-1}$ and $400 \mathrm{~cm}^{-1}$ as Nujol mulls on $\mathrm{KBr}$ discs. UV/vis spectra were measured on a Cary $1 \mathrm{C}$ spectrophotometer within the range $200-800 \mathrm{~nm}$. Elemental and thermal analyses were performed by the Korea Research Institute of Chemical Technology, Daejeon, Korea. The free ligand $\mathbf{L 1}$ and precursor complex [Ni(L1)] $\left(\mathrm{ClO}_{4}\right)_{2}$ were prepared according to the literature procedure. ${ }^{1}$ The macrocyclic ligand $\mathbf{L 1}$ is one out of the 16 possible diastereoisomers of $\mathbf{L}$.

Caution! The perchlorate salts used in this study are potentially explosive and should be handled in small quantities.

Synthesis of 1. To a DMF solution of $[\mathrm{Ni}(\mathbf{L 1})]\left(\mathrm{ClO}_{4}\right)_{2}(59 \mathrm{mg}$, $0.1 \mathrm{mmol}$ ) was added an aqueous solution of $\mathrm{H}_{4}$ thftc. The mixture was allowed in an open beaker at room temperature. Pink crystals of 1 were obtained in two weeks. Suitable crystals of 1 for X-ray diffraction studies and other measurements were manually collected under a microscope. Yield $>90 \%$. Anal. Calcd. for $\mathrm{C}_{56} \mathrm{H}_{104} \mathrm{Ni}_{2} \mathrm{~N}_{8} \mathrm{O}_{24}$ : C, 48.36; H, 7.54; N, 8.06; Found C, 48.66; H, 7.66; N, 8.34. IR (Nujol, $\left.\mathrm{cm}^{-1}\right): 3460(\mathrm{vOH}), 3243$, $3160(v \mathrm{NH}), 1712\left(v_{\mathrm{as}} \mathrm{COO}\right.$ from $\left.\mathrm{COOH}\right), 1591,1527\left(v_{\mathrm{as}} \mathrm{COO}\right.$ from $\left.\mathrm{COO}^{-}\right), 1300\left(v_{\mathrm{s}} \mathrm{COO}\right.$ from $\left.\mathrm{COO}^{-}\right)$.

$\mathrm{X}$-ray Crystallography. A summary of selected crystallographic data and structure refinement for $\mathbf{1}$ is given in Table 1. X-ray data were collected on a Nonius Kappa CCD diffractometer, using graphite monochromated $\mathrm{MoK}_{\alpha}$ radiation $(\lambda=$ 
Table 1. Crystal data and structure refinement for $\mathbf{1}$

\begin{tabular}{ll}
\hline Empirical formula & $\mathrm{C}_{56} \mathrm{H}_{104} \mathrm{~N}_{8} \mathrm{Ni}_{2} \mathrm{O}_{24}$ \\
Formula weight & 1390.89 \\
Temperature (K) & $150(1)$ \\
Wavelength & $0.71073 \AA$ \\
Crystal system & Triclinic \\
Space group & $\mathrm{P} \overline{1}$ \\
Unit cell dimensions & $\mathrm{a}=9.4823(3) \AA$ \\
& $\mathrm{b}=12.8713(8) \AA$ \\
& $\mathrm{c}=14.3230(10) \AA$ \\
& $\alpha=77.184(2)^{\circ}$ \\
& $\beta=72.937(4)^{\circ}$ \\
Volume & $\gamma=77.804(4)^{\circ}$ \\
$Z$ & $1609.38(16) \AA^{3}$ \\
Density (calcd) & 1 \\
Absorption coefficient & $1.435 \mathrm{Mg} / \mathrm{m}^{3}$ \\
Independent reflections & $0.670 \mathrm{~mm}^{-1}$ \\
Goodness-of-fit on $F^{2}$ & $6952[\mathrm{R}(\mathrm{int})=0.0601]$ \\
Final R indices $[\mathrm{I}>2 \sigma(\mathrm{I})]$ & 1.036 \\
$\mathrm{R}$ indices (all data) & $\mathrm{R}_{1}=0.0558, w \mathrm{R}_{2}=0.1233$ \\
\hline
\end{tabular}

Table 2. Hydrogen bonds for $\mathbf{1}\left(\AA\right.$ and $\left.^{\circ}\right)$

\begin{tabular}{lllll}
\hline \multicolumn{1}{c}{$\mathrm{D}-\mathrm{H} \cdots \mathrm{A}$} & $\mathrm{d}(\mathrm{D}-\mathrm{H})$ & $\mathrm{d}(\mathrm{H} \cdots \mathrm{A})$ & $\mathrm{d}(\mathrm{D} \cdots \mathrm{A})$ & $<(\mathrm{DHA})$ \\
\hline $\mathrm{N} 1-\mathrm{H} 1 \cdots \mathrm{O} 6$ & 0.93 & 2.25 & $3.103(4)$ & 152.5 \\
$\mathrm{~N} 2-\mathrm{H} 2 \cdots \mathrm{O} 2$ & 0.93 & 2.09 & $2.952(4)$ & 153.0 \\
$\mathrm{~N} 3-\mathrm{H} 3 \cdots \mathrm{O} 1 \mathrm{~W} 33$ & 0.93 & 2.40 & $3.252(4)$ & 151.6 \\
$\mathrm{~N} 4-\mathrm{H} 4 \mathrm{~A} \cdots \mathrm{O} 4 \# 4$ & 0.93 & 2.06 & $2.970(4)$ & 166.8 \\
$\mathrm{O} 2 \mathrm{~W}-\mathrm{H} 2 \mathrm{WA} \cdots \mathrm{O} 2$ & $0.94(6)$ & $1.83(6)$ & $2.770(4)$ & $174(5)$ \\
$\mathrm{O} 5-\mathrm{H} 5 \mathrm{O} \cdots \mathrm{O} 1 \mathrm{O}$ & $0.81(4)$ & $1.84(5)$ & $2.646(4)$ & $174(5)$ \\
$\mathrm{O} 8-\mathrm{H} 8 \mathrm{O} \cdots \mathrm{O} 3$ & $1.05(6)$ & $1.44(6)$ & $2.448(4)$ & $159(5)$ \\
$\mathrm{O} 10-\mathrm{H} 10 \mathrm{~W} \cdots \mathrm{O} 2 \mathrm{~W}$ & $0.73(5)$ & $2.00(5)$ & $2.722(4)$ & $169(5)$ \\
$\mathrm{O}(10)-\mathrm{H}(10 \mathrm{O}) \cdots \mathrm{O}(4) \# 5$ & $0.86(6)$ & $1.89(6)$ & $2.714(4)$ & $159(5)$ \\
\hline $\mathrm{S} y m$
\end{tabular}

Symmetry transformations used to generate equivalent atoms: \#3 -x, $-\mathrm{y}+1,-\mathrm{z}+1 \quad \# 4-\mathrm{x}+1,-\mathrm{y},-\mathrm{z}+1 \quad \# 5 \mathrm{x}-1, \mathrm{y}, \mathrm{z}$

$0.71073 \AA$ ). A combination of $1^{\circ} \phi$ and $\omega$ (with $\kappa$ offsets) scans were used to collect sufficient data. The data frames were integrated and scaled using the Denzo-SMN package. ${ }^{9}$ The structure was solved and refined using the SHELXTL $\backslash P C$ V6.1 package. ${ }^{10}$ Refinement was performed by full-matrix least squares on $F^{2}$ using all data (negative intensities included). Hydrogen atoms were included in calculated positions. There are two different types of discrete centrosymmetric nickel(II) macrocycles and four water molecules in the formula unit. Only the two unique water molecules are shown in Figure 1. The dication is linked to the dianion by hydrogen bonds through lattice water molecules.

\section{Results and Discussion}

The pink complex 1 was obtained by reacting $[\mathrm{Ni}(\mathbf{L 1})]\left(\mathrm{ClO}_{4}\right)_{2}$ with $\mathrm{H}_{4}$ thftc in $\mathrm{DMF} / \mathrm{H}_{2} \mathrm{O}$, followed by slow evaporation of the resulting solution. The complex $\mathbf{1}$ was indefinitely stable in air and was insoluble in DMF or $\mathrm{H}_{2} \mathrm{O}$. Figure 1 shows the

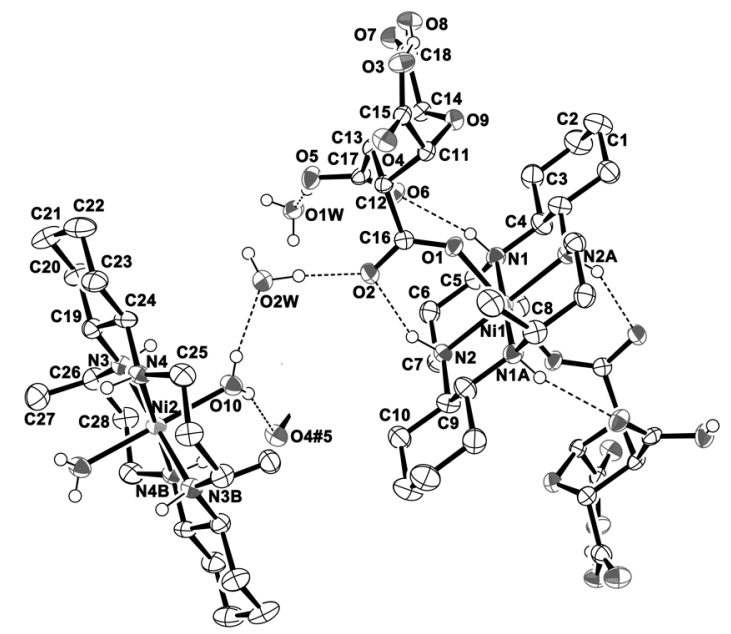

Figure 1. Molecular structure of 1 with atom-labeling scheme. Hydrogen atoms other than those participating in hydrogen bonding are omitted for clarity. Selected bond distances $(\AA)$ and angles $\left({ }^{\circ}\right)$ : Nil-N1, 2.079(3); Ni1-N2, 2.058(3); Ni1-O1, 2.134(2); O3-C15, 1.283(4); O4-C15, 1.236(4); O7-C18, 1.220(5); O8-C18, 1.306(4); Ni2-N3, 2.084(3); Ni2-N4, 2.066(3); Ni2-O10, 2.163(3); N2-Ni1-N1, 95.28(11); N2\#1Ni1-N1, 84.72(11); N2-Ni1-O1\#1, 86.93(10); N1-Ni1-O1\#1, 95.84 (10); N2-Ni1-O1, 93.07(10); N1-Ni1-O1, 84.16(10); N4-Ni2-N3, 84.30(11); N4-Ni2-N3\#2, 95.70(11); N4-Ni2-O10, 90.65(12); N3Ni2-O10, 86.44(11); N4-Ni2-O10\#2, 89.35(11); N3-Ni2-O10\#2, 93.56(11). Symmetry code: \#1 -x+1, -y+1, -z \#2 -x, -y, -z+1.

molecular structure of $\mathbf{1}$ determined by single crystal X-ray crystallography. Selected bond distances and angles are listed in Figure 1. The structure of $\mathbf{1}$ is composed of a macrocyclic diaqua nickel(II) dication $\left[\mathrm{Ni}(\mathbf{L 1})\left(\mathrm{H}_{2} \mathrm{O}\right)_{2}\right]^{2+}$ and macrocyclic bis $\left(\mathrm{H}_{2}\right.$ thftc) nickel(II) dianion $\left[\mathrm{Ni}(\mathbf{L 1}) \text { bis }\left(\mathrm{H}_{2} \text { thftc }\right)\right]^{2-}$. Two aqua ligands successfully reside on the nickel(II) ion axially in the dication, where the hydrogen bonds play a role in supporting the coordination of water molecules to the central nickel(II) ion (Table 2). ${ }^{4}$ The macrocyclic ligand skeleton of $\mathbf{L 1}$ takes the most stable "trans III" conformation and the nickel(II) ion lies on an inversion center in the dication. The Ni-N distances of 2.079(3), 2.058(3) $\AA$ and the Ni-O distance of 2.134(2) $\AA$ are similar to those expected for octahedral macrocyclic nickel(II) complexes. ${ }^{4,11}$ The Ni-N distances follow a general trend that weaker Ni-N bonds are involved in an octahedral nickel(II) system $(\mathrm{Ni}-\mathrm{N}=2.07-2.10 \AA)$ than in a square planar nickel(II) system $(\mathrm{Ni}-\mathrm{N}=1.88-1.91 \AA) .{ }^{12,13}$ In the dianion, the nickel(II) ion is coordinated by the macrocyclic ligand $\mathbf{L 1}$ and $\mathrm{H}_{2}$ thftc axial ligands, resulting in the structure of an axially elongated octahedron. Similarly in the dication, an inversion center exists on the central nickel(II) ion. Two monodentate $\mathrm{H}_{2}$ thftc ligands axially coordinate to the central nickel(II) ion, which is sixcoordinate in the blue high-spin form. Although the free acid $\mathrm{H}_{4}$ thftc is introduced during the synthesis of $\mathbf{1}$, always two of the four carboxylic acids of $\mathrm{H}_{4}$ thftc are deprotonated and the resulting $\mathrm{H}_{2}$ thftc is involved in the formation of the macrocyclic nickel(II) dianion. In the $\mathrm{H}_{2}$ thftc ligand, one of the carboxylic acid groups participates in hydrogen bonding interaction intramolecularly with a neighborhood carboxylate group. It is generally understood that the diverse coordination modes and shapes of polycarboxylate ligands can exist depending on the degree 
(a)

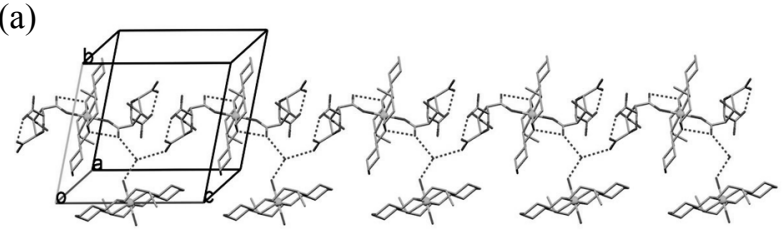

(b)

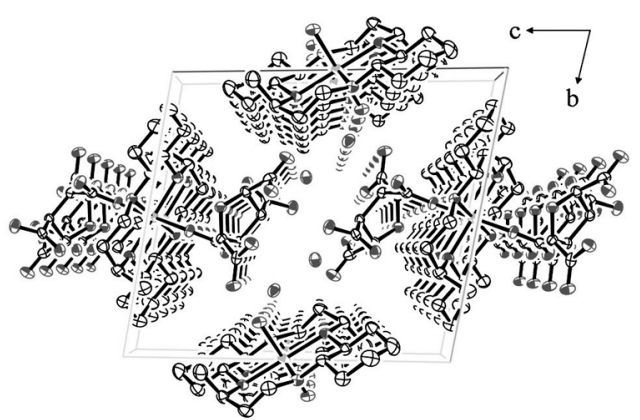

Figure 2. 1D hydrogen bonded chain running toward crystallographic $c$ direction (a) and crystal packing diagram (b) of $\mathbf{1}$.

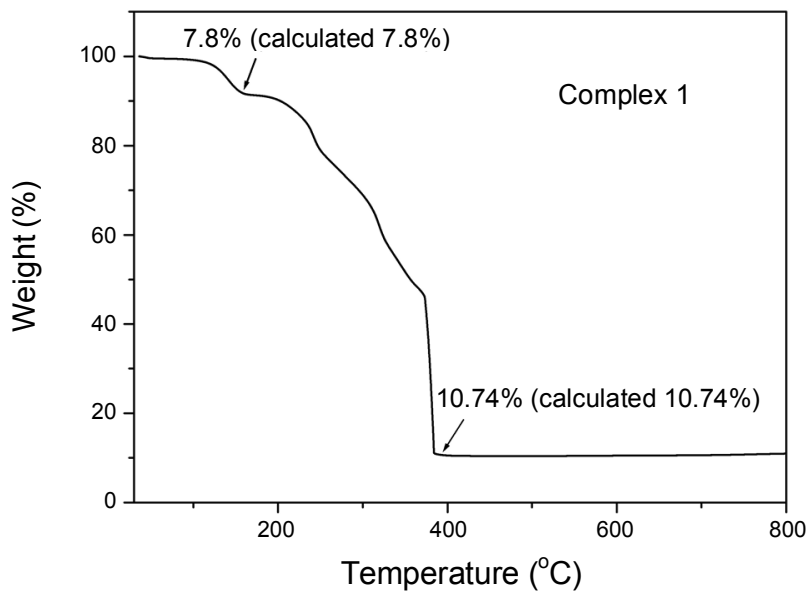

Figure 3. TGA curve for $\mathbf{1}$.

of deprotonation and the types of hydrogen bonds involved. ${ }^{14,15}$ The Ni-N distances of 2.084(3), 2.066(3) $\AA$ and the Ni-O distance of 2.163(3) $\AA$ in the macrocyclic nickel(II) dianion are normal and similar to those of octahedral macrocyclic nickel(II) complexes. ${ }^{16,17}$ The macrocyclic nickel(II) dications are connected to the macrocyclic nickel(II) dianions by hydrogen bonds through lattice water molecules and they are charge balanced (Figure 2, Table 2).

The microanalytical, spectroscopic and thermal results fully support the structure determined by X-ray diffraction and give evidences for the presence of the macrocycle, $\mathrm{H}_{2}$ thftc ligands and lattice water molecules. The infrared spectrum of 1 indicates the characteristic bands of the carboxylic acid ligand at 1712 $\left(v_{\mathrm{as}} \mathrm{COO}\right.$ from $\left.\mathrm{COOH}\right), 1591,1527 \mathrm{~cm}^{-1}\left(v_{\mathrm{as}} \mathrm{COO}\right.$ from $\mathrm{COO}^{-}$) and $\left(v_{\mathrm{s}} \mathrm{COO}\right) 1300 \mathrm{~cm}^{-1}$. Two weak bands at $3243 \mathrm{~cm}^{-1}$ and $3160 \mathrm{~cm}^{-1}$ can be assigned to the N-H stretchings of the macrocycle. The broad band at $3460 \mathrm{~cm}^{-1}$ is originated from $\mathrm{O}-\mathrm{H}$ stretching of the lattice water molecules. The solid state elec- tronic spectrum of $\mathbf{1}$ in the visible region shows three bands at 341,512 and $679 \mathrm{~nm}$. The bands at 341 and $512 \mathrm{~nm}$ are assignable to the ${ }^{3} \mathrm{~B}_{1 \mathrm{~g}} \rightarrow{ }^{3} \mathrm{E}_{\mathrm{g}}^{\mathrm{c}}$ and ${ }^{3} \mathrm{~B}_{1 \mathrm{~g}} \rightarrow{ }^{3} \mathrm{E}_{\mathrm{g}}{ }^{\mathrm{b}}$ transitions, respectively, and the band at $679 \mathrm{~nm}$ is assignable to the combination of ${ }^{3} \mathrm{~B}_{1 \mathrm{~g}} \rightarrow{ }^{3} \mathrm{~B}_{2 \mathrm{~g}}$ and ${ }^{3} \mathrm{~B}_{1 \mathrm{~g}} \rightarrow{ }^{3} \mathrm{~A}_{2 \mathrm{~g}}{ }^{\mathrm{a}}$ transitions, which is the characteristic spectrum expected for a high-spin nickel(II) ion in a $D_{4 \mathrm{~h}}$ environment. ${ }^{4,11,18}$ TGA curve for 1 shows a first weight loss of $7.8 \%$ (calculated $7.8 \%$ ) over $100-200{ }^{\circ} \mathrm{C}$, corresponding to the loss of six lattice water molecules. Final residues (observed $10.74 \%$, calculated $10.74 \%$ ) were remained above $410{ }^{\circ} \mathrm{C}$ with $2 \mathrm{NiO}$ composition (Figure 3 ).

In conclusion, we have prepared and fully characterized the new macrocyclic nickel(II) complex salt 1 in which each nickel (II) ion adopts an axially elongated octahedral coordination environment. Specifically in the dication, two aqua ligands coordinate to the central nickel(II) ion axially, resulting in the formation of a rare trans-diaqua macrocyclic nickel(II) species. The aqua ligands in the dication are supported by the presence of hydrogen bonds. In the macrocyclic nickel(II) dianion, $\mathrm{H}_{2}$ thftc ligands coordinate to the central nickel(II) ion axially. The macrocyclic nickel(II) dications and the macrocyclic nickel(II) dianions are linked through lattice water molecules by hydrogen bonding to form a 1D polymer.

Supplementary Material. Crystallographic data for the structure have been deposited with Cambridge Crystallographic Data Center (Deposition No. CCDC 747975 for 1). These data can be obtained free of charge via http://www.ccdc.cam.ac.uk/ conts/retrieving.html or from CCDC, 12 Union Road, Cambridge CB2 1EZ, UK, fax: 441223 336033, email: deposit@, ccdc.cam.ac.uk.

Acknowledgments. This work was supported by the Korea Research Foundation Grant funded by the Korean Government (MOEHRD), Basic Research Promotion Fund) (KRF-2008521-C00137).

\section{References}

1. Kang, S.-G.; Kweon, J. K.; Jung, S.-K. Bull. Korean Chem. Soc. 1991, 12, 483 .

2. Anichini, A.; Fabbrizzi, L.; Paoletti, P. Inorg. Chim. Acta 1977, $24,21$.

3. Vigee, G. S.; Watkins, C. L.; Bowen, H. F. Inorg. Chim. Acta 1979, 35, 255

4. Mochizuki, K.; Kondo, T. Inorg. Chem. 1995, 32, 6241.

5. Kim, J. C.; Fettinger, J. C.; Kim, Y. I. Inorg. Chim. Acta 1999, $286,67$.

6. Hay, R. W.; Jeragh, B.; Ferguson, F.; Kaitner, B.; Ruhl, B. L. J. Chem. Soc., Dalton Trans. 1982, 1531.

7. Fabbrizzi, L. Inorg. Chem. 1977, 18, 438.

8. Szalda, D. J.; Fujita, E.; Sanzenbacher, R.; Paulus, H.; Elisa, H. Inorg. Chem. 1994, 33, 5855.

9. Otwinowski, Z.; Minor, W. In Methods in Enzymology, Macromolucular Crystallography, Part A, Carter, C. W., Sweet, R. M., Eds.; Academic Press: London, 1997; vol. 276, pp 307-326.

10. Sheldrick, G. M. SHELXTL\PC V6.1, Bruker Analytical X-ray Systems, Madison, WI, 2001.

11. Kim, J. C.; Cho, J.; Kim, H.; Lough, A. J. Chem. Commun. 2004, 
1796.

12. Suh, M. P.; Kang, S.-G. Inorg. Chem. 1988, 27, 2544.

13. Misra, T. K.; Chung, C.-S.; Cheng, J.; Lu, T.-H. Polyhedron 2001, 20, 3149.

14. Kim, J. C.; Lough, A. J.; Kim, H. Inorg. Chem. Commun. 2002, 5,771 .
15. Park, H.; Jeong, M. H.; Kim, J. C.; Lough, A. J. Bull. Korean Chem. Soc. 2007, 28, 303.

16. Choi, K.-Y.; Chun, K. M.; Suh, I.-H. Polyhedron 2001, $20,57$.

17. Choi, K.-Y.; Kim, K.-J. Polyhedron 2008, 27, 1310.

18. Martin, L. Y.; Sperati, C. R.; Busch, D. H. J. Am. Chem. Soc. 1977, 99, 2968. 